\title{
Simple and Low Cost Design of Infusion Device Analyzer Based on Arduino
}

\author{
Nikmatul Jannah $^{1}$, Syaifudin ${ }^{1}$, Liliek Soetjiatie ${ }^{1}$, Muhammad Irfan Ali $^{2}$ \\ ${ }^{1}$ Department of Medical Electronics Engineering Technology Politeknik Kesehatan Kementerian Kesehatan Surabaya \\ Jl. Pucang Jajar Timur No. 10, Surabaya (60282), Indonesia \\ ${ }^{2}$ University of Punjab,Department of Electrical Engineering Information Technology,Lahore,Pakistan \\ North Underpass, Quaid-i-Azam Campus, Lahore, Punjab 54590, Pakistan \\ E-mail: nikmatulj10@gmail.com
}

\section{Article Info \\ History Articles: \\ Receive Mei 15, 2020 \\ Revised August 10, 2020 \\ Received August 30, 2020}

\begin{abstract}
In the medical world, patient safety is a top priority. The number of workloads and frequency of use in the long term will affect the accuracy and precision of the equipment. Therefore calibration is needed, namely the measurement activities to determine the truth of the appointment value of measuring instruments and measuring materials based on the standards of the Minister of Health Regulation No. 54/2015. The purpose of this study is to design an infusion device analyzer to measure the flowrate parameter using the Arduino microcontroller. The main advantage of this study is that the system can display three calibration results in one measurement at the same setting. The results of the calibration will determine the feasibility of an infusion pump or a syringe pump. This study uses the flow rate formula, which is applied to the water level system to obtain the calibration results. The infrared photodiode sensor will detect the flow of water in the chamber that comes from the infusion or syringe pump. Furthermore, the sensor output will be processed by the microcontroller, and the reading results are displayed on the liquid crystal display. The average measurement at a setting of $10 \mathrm{ml} / \mathrm{hour}$ is 9.36 $\mathrm{ml} /$ hour, at a setting of $50 \mathrm{ml} /$ hour is $46.64 \mathrm{ml} /$ hour, and at a setting of $100 \mathrm{ml} / \mathrm{hour}$ is $96.04 \mathrm{ml} / \mathrm{hour}$. Based on available data, this tool has an average error value of $5.69 \%$, where the value exceeds the tolerance limit allowed by ECRI, which is $\pm \mathbf{5 \%}$.
\end{abstract}

\author{
The corresponding author: \\ Syaifudin \\ Department of Medical Electronics Engineering Technology \\ Politeknik Kesehatan Kementerian Kesehatan Surabaya \\ J1. Pucang Jajar Timur No. 10, Surabaya (60282), Indonesia \\ E-mail: nyong74@yahoo.com
}

This jobopen access articles and licensed under Creative Commons Attribution-Non-Commercial $4.0 \quad$ License International,

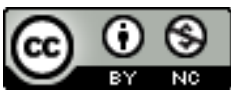

\section{INTRODUCTION}

In the hospital, intravenous therapy is an important therapy for patients and the most common curing [1][2]. A nurse sets an IV infusion device up according to the doctor's medical order [1]. Intravenous infusion devices are medical devices that function to deliver fluids, including medicines and nutrients into the patient's circulatory system continuously by controlling the volume or rate of fluid flow precisely and accurately through a needle to treat dehydration due to a disease or after excessive activity by distributing antibiotics or certain [3][4]. These drugs must be given at a certain time and speed of at least $0.5 \mathrm{ml} /$ hour. This level cannot be reached accurately with normal intravenous infusion [5]. The medical devices commonly used for administering such fluids are infusion pumps and syringe pumps. Both devices have an important function, which is an alarm system that will sound if the infusion speed exceeds or is lower than a certain range. Therefore, the detection and calculation of speed are related to the accuracy of the infusion device [2]. The infusion pump and syringe pump are very efficient, fast, and precise methods [6]. The advantage of using an infusion pump or syringe pump is that medical personnel do not need to count the number of drops or volumes manually because in both devices there are already settings for flow rate and volume that will automatically enter the liquid at a constant speed and for a certain time.

In the health industry, be it a hospital or medical equipment factory, patient safety is a top priority. Intravenous therapy can cause several problems such as air embolism, excess fluid, and changes in the droplet rate. Due to changes in droplet rate, lack of infusion causes sub-optimal therapy, dehydration, or metabolic disorders. While excessive infusion can cause speed shock, electrolyte imbalance, high blood pressure, or metabolic disorders [7]. If the flow rate and volume is given to the patient 
are not controlled (overdose or fluid flow rate is too high), it can cause hypertension, heart failure, or pulmonary edema and when an occlusion occurs, drugs or nutrients cannot flow into the patient's blood vessels so it becomes inefficient and ineffective [3]. In addition, if air bubbles in the infusion pump or syringe pump enter the patient's venous system can cause serious problems and often fatal. Air bubbles can also spread to the lungs, heart, and brain and cause respiratory failure, stroke, or heart attack [5][8]. This will cause delayed treatment, pain in the patient, or even seriously endanger the physical and mental health of the patient, and medical malpractice occurs beyond repair [9], in the many past reports of functional failure in the syringe pump. Statistical results show that $39 \%$ of errors occur when giving drugs, $10 \%$ errors appear in pharmacies, and $38 \%$ errors are made when infusing drugs, $13 \%$ for several other reasons [10]. The use of medical devices with a large workload and the frequency of use, in the long run, will affect the accuracy and accuracy of the device, so it is necessary to re-measure with the aim to minimize errors in the provision of intravenous therapy to patients. Re-measurement in question is to do testing and calibration, especially on medical devices. Calibration is an illumination activity to determine the truth of the appointment value of the measuring instrument and or measuring material [11]. Equipment testing and calibration are useful to ensure the accuracy, effectiveness, and lifetime of the equipment to achieve the highest level of quality control [12]. The instrument used to calibrate the infusion pump, and syringe pump is the Infusion Device Analyzer, which measures the flow rate, volume, and occlusion pressure. The reference used as a guideline when calibrating the infusion pump and syringe pump is ECRI 4160595. Allowable flow rate measurements are $\pm 5 \%$ for critical patients, $\pm 10 \%$ for general patients, and $\leq 20$ Psi for occlusion pressure [13]. This tool is very important for the hospital to have so that the equipment is maintained and maintained its quality and accuracy.

In this research, the writer wants to propose an infusion device analyzer design with flowrate parameters. The reason the authors chose the flowrate parameter is that these parameters are the main parameters both in the infusion pump and syringe pump. In doing this research, the authors used previous research as a reference and benchmark for completing research. The existence of previous research makes it easier for writers to formulate theories and concepts and determine systematic steps. Previous research had been conducted by three students of the Electromedical Engineering of Poltekkes Surabaya, namely Yanu Eko Prastiyono (2011) with the title flowrate calibration tool through the volume in microcontroller-based infusion pumps, Adhif Ristianto (2012) with the title pc-based syringe pump calibration tool and Safira Pintasari (2019) with the title design and build infusion pump analyzer. In this study, the authors used the same sensor as the three researchers, namely the infrared photodiode sensor. This research will produce three calibration results in one measurement at the same setting, using a water level system. The water level is used to measure the height of the water from the bottom to the surface. To find out the flow rate at the infusion pump or syringe pump, the writer uses the formula of the water flow rate by determining the volume of water, setting the flow rate on the device measured, and the length of time of measurement.

This article consists of 5 parts. Part I is an introduction, Part II contains the materials and methods to be carried out. Part III is the results obtained in this study. Part IV is a discussion of finding, and Part V is a conclusion.

\section{MATERIALS AND METHODS}

\section{A. Experimental Setup}

This study uses the TOP-5300 syringe pump as a tool to be measured. Data collection is carried out sequentially, starting from low to high flow rates.

\section{B. Materials and Tools}

This study uses photodiode and infrared sensors as flow rate detectors. A two-channel solenoid valve $12 \mathrm{VDC}$ was used to close and open water flow. A software Arduino (Version 1.8.11), Arduino Nano V3.0, was used to develop the program of a microcontroller. Finally, an LCD character $2 \times 12$, as a display and $\mathrm{I} 2 \mathrm{C}$ as a communication between a microcontroller and display.

\section{Experiment}

In this study, researchers measured the output of the circuit using a syringe pump at settings of 10,50 , and $100 \mathrm{ml} /$ hour. Data collection was done 1-time measurement at a flow rate of 10 $\mathrm{ml} /$ hour and two times measurement at a flow rate of 50 and 100 $\mathrm{ml} /$ hour.

\section{The Diagram Block}

When the appliance is turned on, the power supply will supply voltage to the entire circuit. The sensor will detect the presence or absence of water flowing in the tube chamber from the infusion or syringe pump. The sensor output will enter the comparator circuit to compare the input voltage of the sensor with the reference voltage. Then the ADC will convert analog data into digital, which is processed by a microcontroller on Arduino Nano. The reading results will be displayed on an LCD character 2004A in the form of a time counting, volume, flow rate, and length of measurement by following the applicable formula. The detailed system is shown in Fig. 1

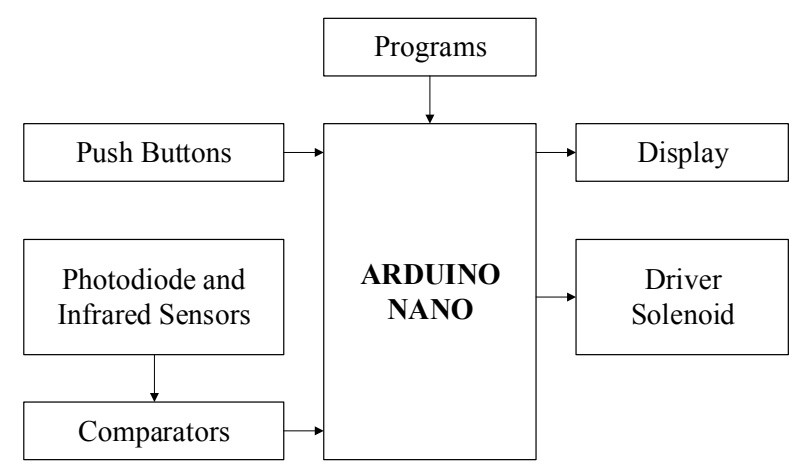

Fig. 1. The diagram block of the IDA with Flowrate Parameters 


\section{E. The Flowchart}

When the device is turned on, the voltage will supply to the entire circuit, and the LCD will initialize. The screen will display the parameter selection. Select the flowrate parameter to measure the flow rate, then press the start button. The solenoid inlet on the device will automatically open, and the sensor will read. The first sensor works as the time counter. When the second sensor is blocked by water, it means that the first measurement time counter is reached and will be processed by the microcontroller on the Arduino Nano. The measurement results will be displayed on the screen in the form of a timer counter, flow rate, volume, and time of measurement. Furthermore, this tool will make the second and third measurements with the same process and settings but with different sensors. When the results of the third measurement appear, the timer will stop, and the solenoid drain will automatically open to drain water. The flow chart of the proposed method is shown in Fig. 2

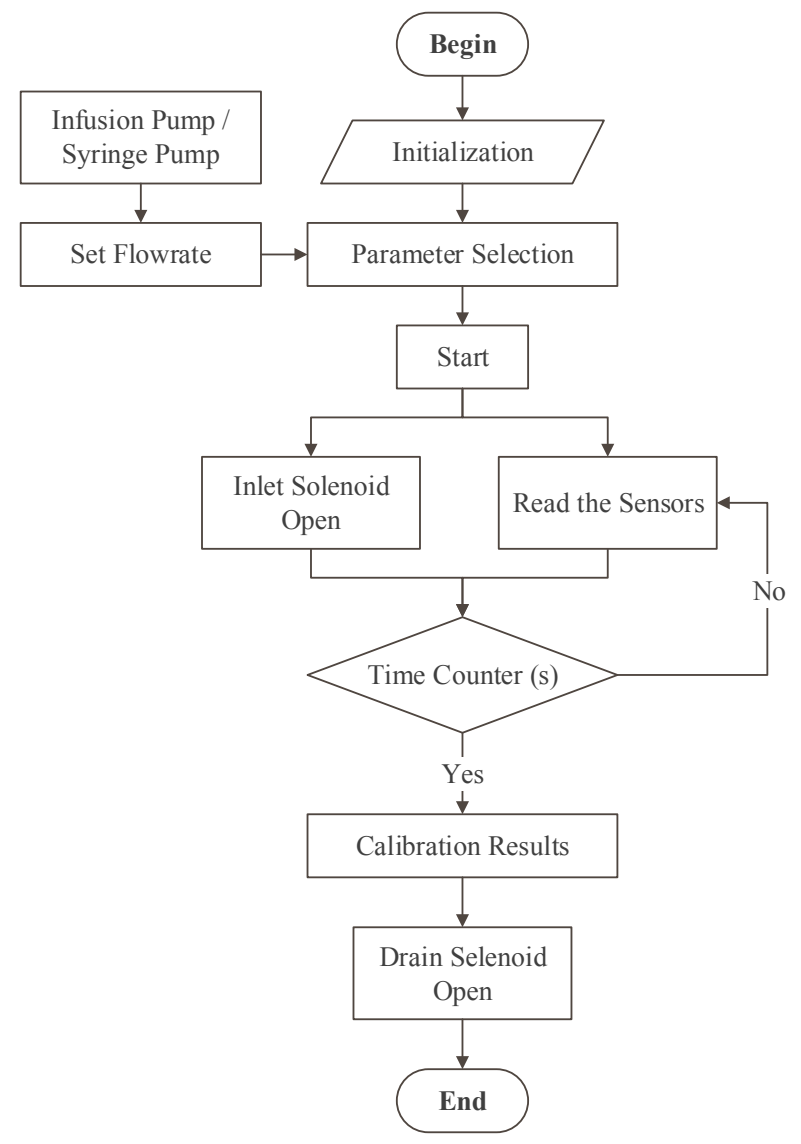

Fig. 2. The Flowchart of the Arduino Program

\section{F. Circuit}

\section{1) Infrared Photodiode and Comparator}

The output voltage of the infrared photodiode will enter the comparator input (pin -) to be compared with the reference voltage originating from the multiturn voltage (pin + ) (Fig. 3). The sensor has two conditions, namely, when the sensor is not blocked by water and when blocked by water. When the sensor voltage is higher than the sensor voltage, it indicates the sensor is not blocked by water. But if the reference voltage is higher than the sensor voltage, it indicates that the sensor is blocked by water [14][15].

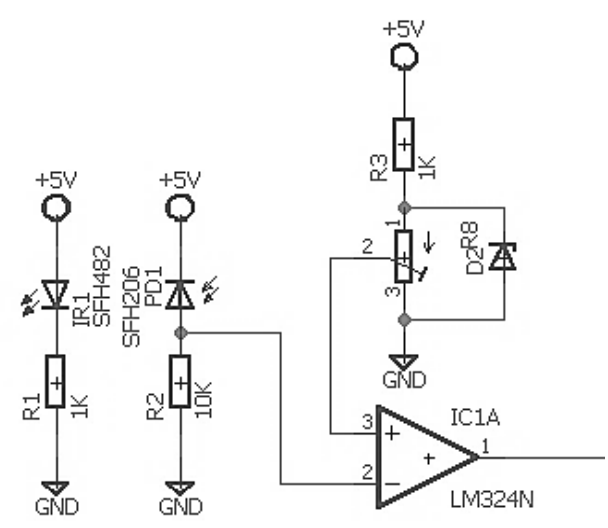

Fig. 3. Infrared Photodiode and Comparator Circuit

\section{2) Solenoid Driver}

The solenoid driver circuit functions to regulate the opening and closing of the flow of water that enters the device during measurement. This circuit is connected to the Arduino microcontroller on digital pins 7 and 8 (Fig. 4).

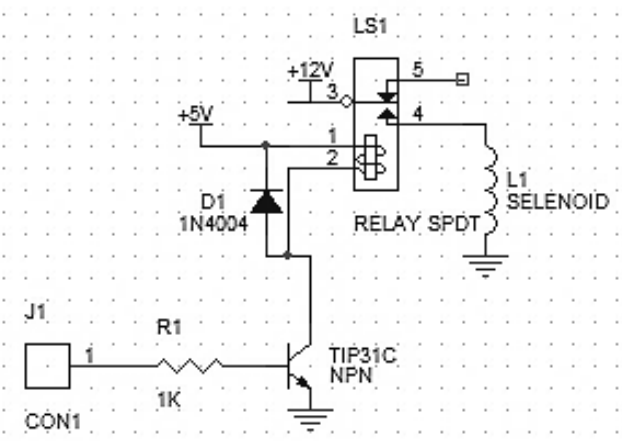

Fig. 4. Solenoid Driver

\section{RESULT}

In this study, the instrument was only tested using a TOP5300 syringe pump without testing it with standard measuring devices. So, it cannot be known whether this tool is suitable for use as a calibrator or not.

\section{A. IDA Design}

Design tools can be seen in Fig. 5. There is a LCD character 2004A as the screen display. It has four pushbuttons consisting of select, enter, start, and reset buttons. At the bottom of the tool there is an inlet as the entrance of liquid from the syringe or infusion pump and Arduino Nano USB connector. On the back, there is a power button and a water drain. Fig. 6 shows the results of a series of solenoid drivers that function to open and close the water flow. In Fig. 7 is the result of a series of infrared 
photodiode sensors and comparators that function for sensor readings.

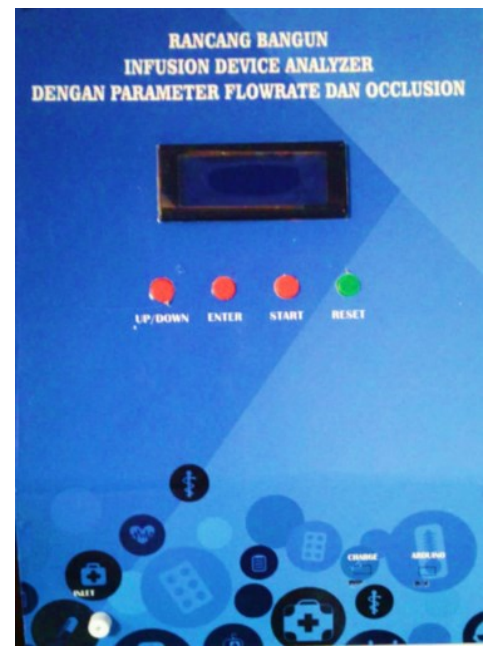

Fig. 5. Infusion Device Analyzer With Flowrate Parameters

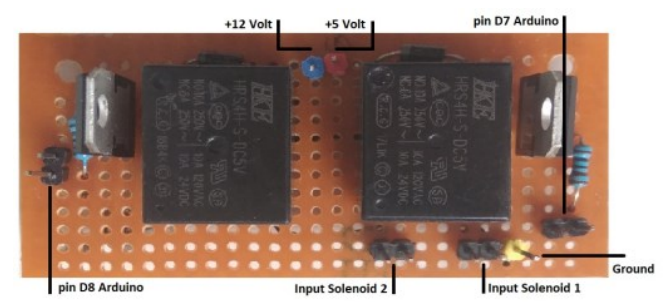

Fig. 6. The Results of the Solenoid Driver Circuit

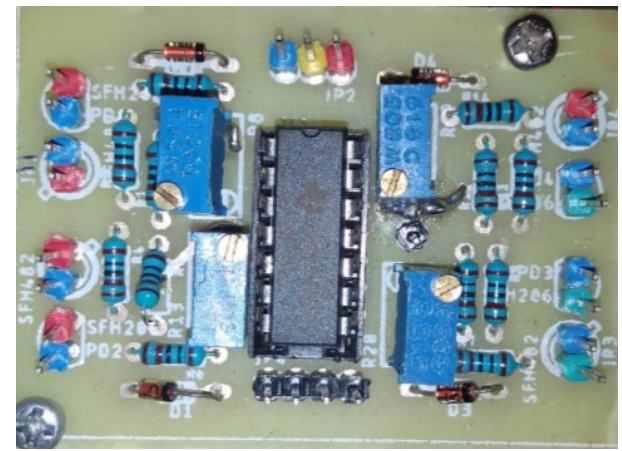

Fig. 7. The Results of the Infrared Photodiode Sensor Circuit and the Comparator

\section{B. Listing Program}

\section{1) Listing Program For Library and Initialization}

\#include $<$ Wire.h $>$

\#include $<$ LiquidCrystal_I2C.h $>$

\#define BACKLIGHT_PIN 13

LiquidCrystal_I2C lcd (0x27,2,1,0,4,5,6,7,3, POSITIVE); int pinSolenoid $1=7$; //solenoid inlet

int pinSolenoid $2=8$; //solenoid drain

int sensorFlow1, sensorFlow2, sensorFlow3, sensorFlow4 = 0 ; int timer, $\mathrm{v}, \mathrm{v} 1=0$;

int kondisi $=1$;

int milidetik, jam;

int detik $=0$; int menit $=0$;

int down $=0$; int enter $=0$; int start $=1$; int reset $=0$;

int $\mathrm{i}=0$; int val $=0$; int $\mathrm{vol}=0$; int kunci $=0$;

const int pinFlow $1=\mathrm{A} 1 ; / /$ start counting

const int pinFlow $2=\mathrm{A} 2$; //sensor 1

const int pinFlow3 $=\mathrm{A} 3$; //sensor 2

const int pinFlow4 $=\mathrm{A} 6$; //sensor 3

const int sw1 $=3$; //down button

const int sw2 $=4$; //enter button

const int sw3 $=5 ; / /$ start button

const int sw4 $=6$; $/ /$ reset button

float Flow1, Flow2, Flow3, Flow4, fr1, fr2, fr3, fr4,

waktuFlow1, waktuFlow2, waktuFlow3, waktuFlow4 =0;

unsigned long waktusekarang, waktu, waktu2, waktu3, waktu4, reset 1, reset 2 , reset 3 , reset $4, w k 1, w k 2, w k 3, w k 4=$ 0

\section{2) Listing Program For Time Counter}

This time counter program can be run when the required initialization is complete.

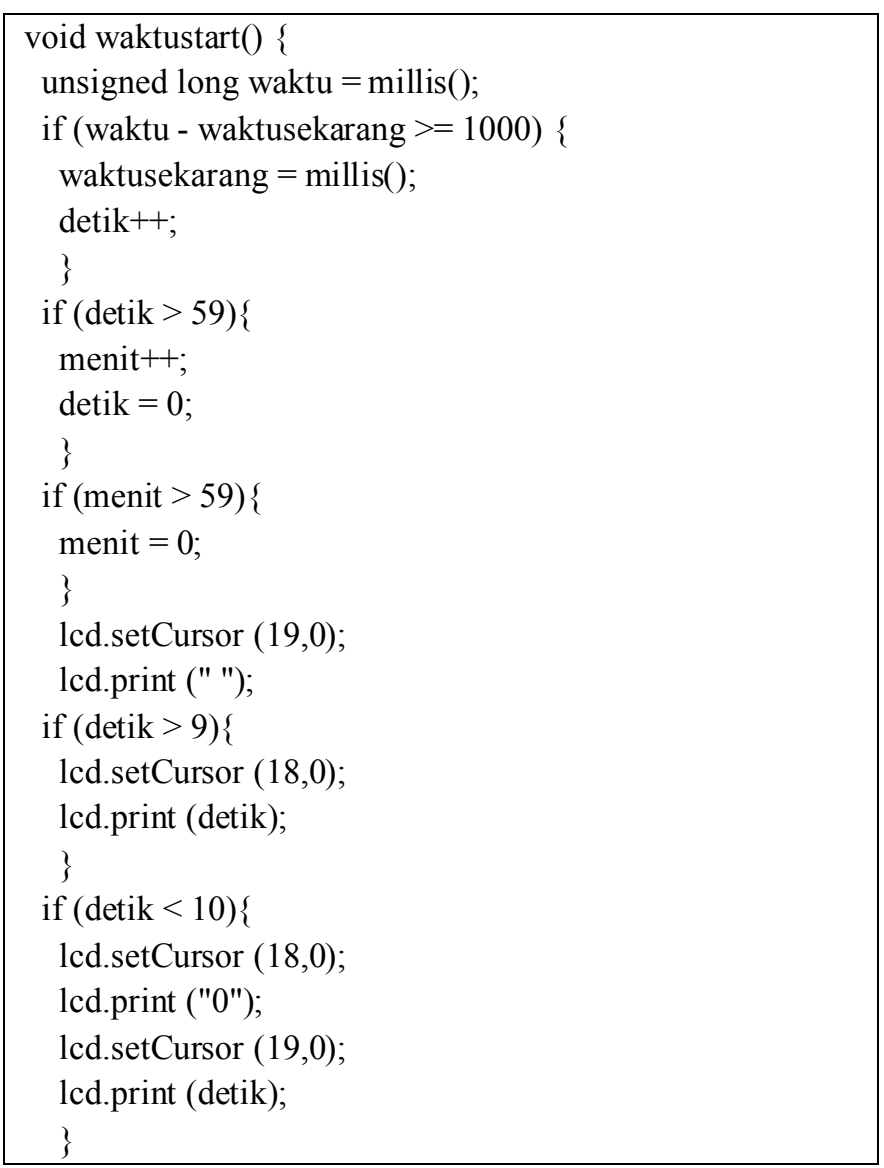




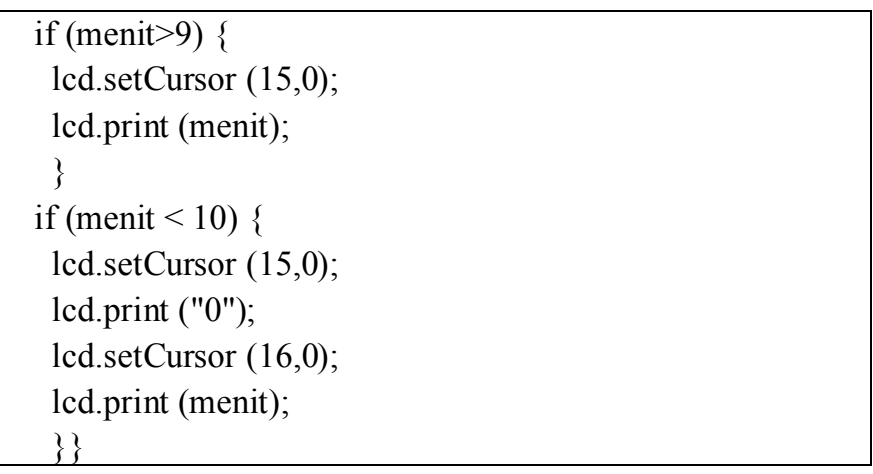

\section{3) Listing Program For Sensor}

When the flowrate setting is selected, the system will automatically enter the "menu06". The LCD character 2004A display will display volume $(\mathrm{V})$, time counter $(\mathrm{T})$, flowrate results (F1, F2 and F3) and the time for each flowrate result.

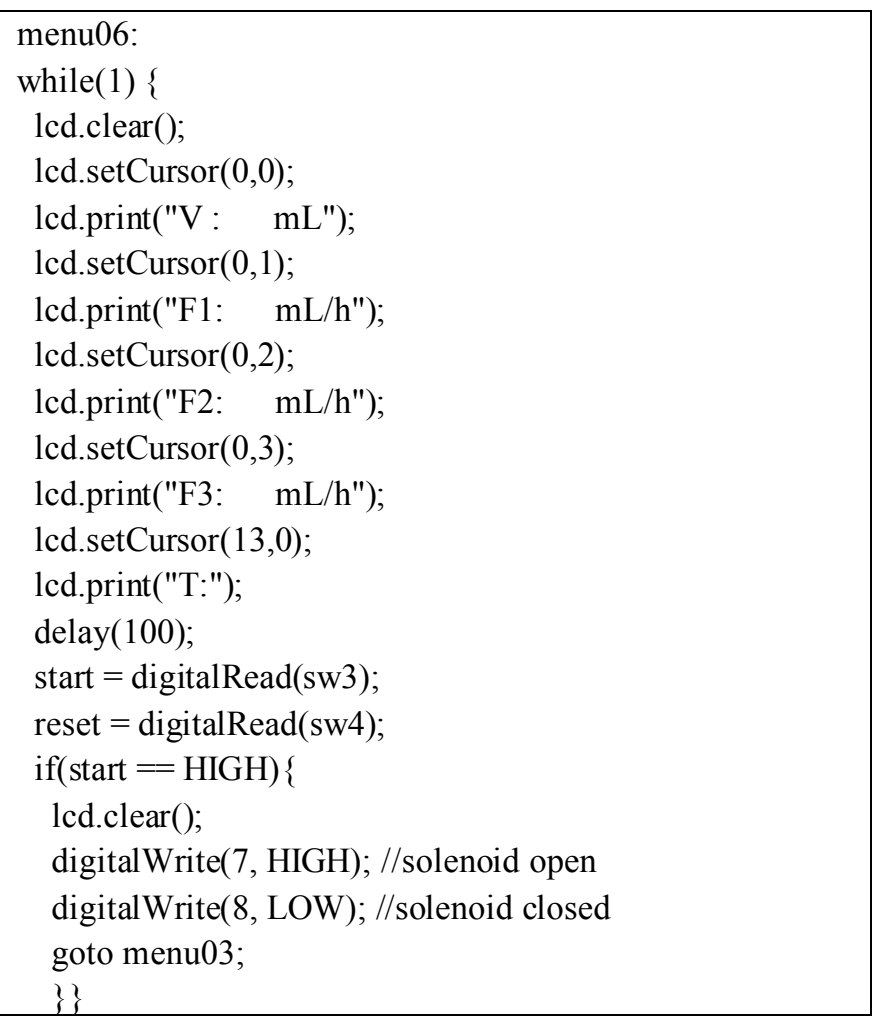

When the start button is pressed, the inlet solenoid will automatically open and the drain solenoid closes and the system will enter menu03 which is a sensor reading program. flowrate sensors enter through analog pins A1, A2, A3 and A6 on Arduino Nano in the form of analog data and can be written in Arduino as follows:

menu03:
while(1) \{
$/ /===============$ Start $=============$

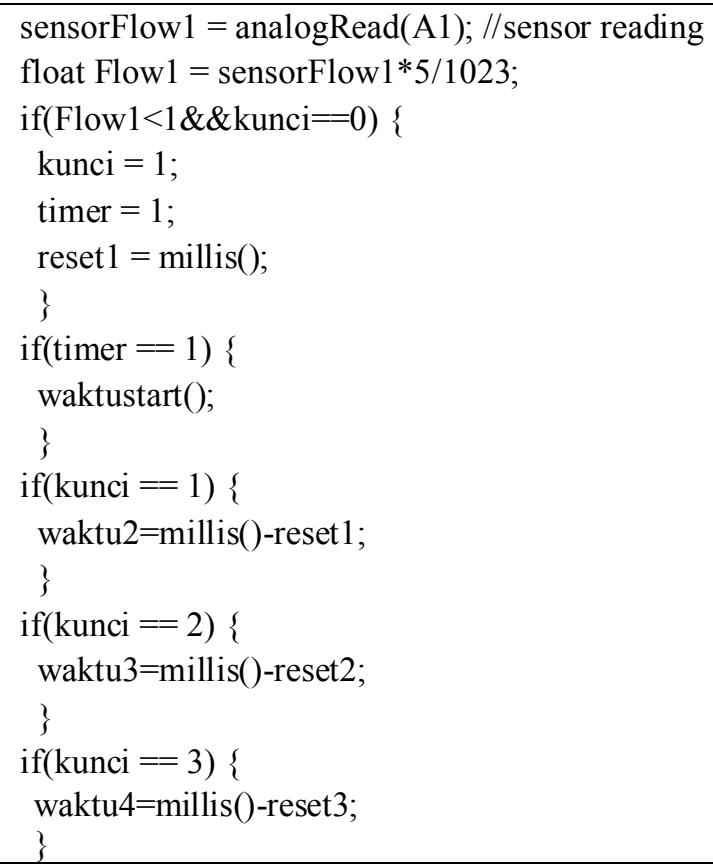

Based on the measurement data of the output voltage on the comparator, the authors make the conditions in the program, namely, if the comparator output voltage is less than 1 Volt, shows logic 0 , and if the output voltage is more than 1 Volt shows logic 1 . So, when the sensor is blocked by water, the microcontroller will get logic 0 . However, if the sensor is not blocked by water, the microcontroller will get logic 1 . The sensor reading program above functions to start the counter. When water gets in the way of the first sensor, the sensor output voltage will go to the ADC and will be converted from the sensor value $(0-1023$ bit $)$ to the voltage value $(0-5 \mathrm{~V})$, the microcontroller will give logic 0 and the time counter program will run.

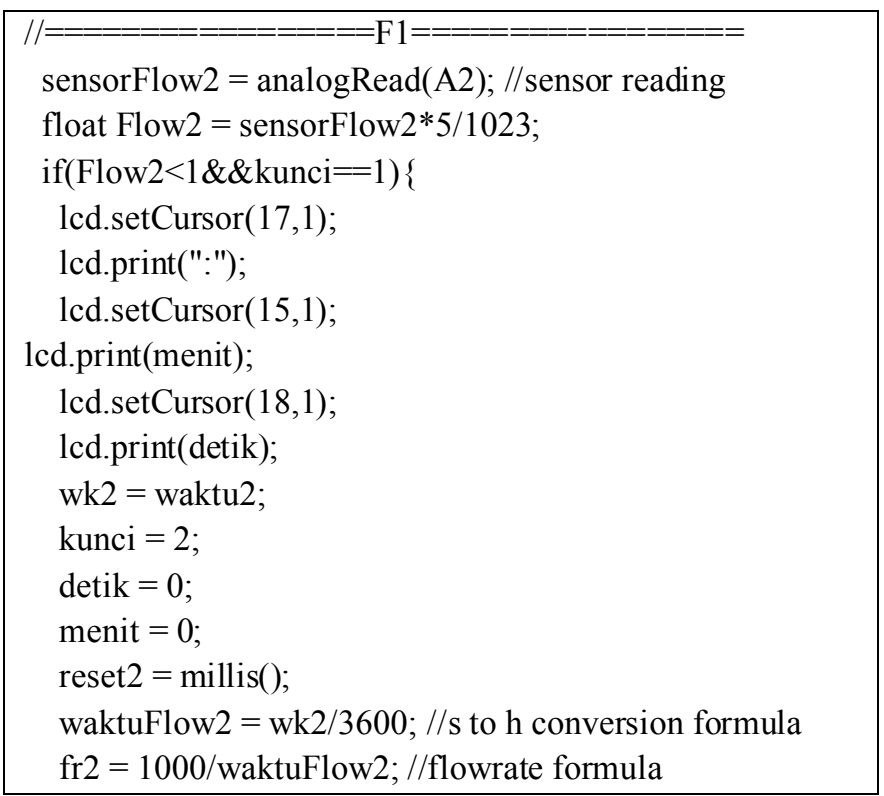




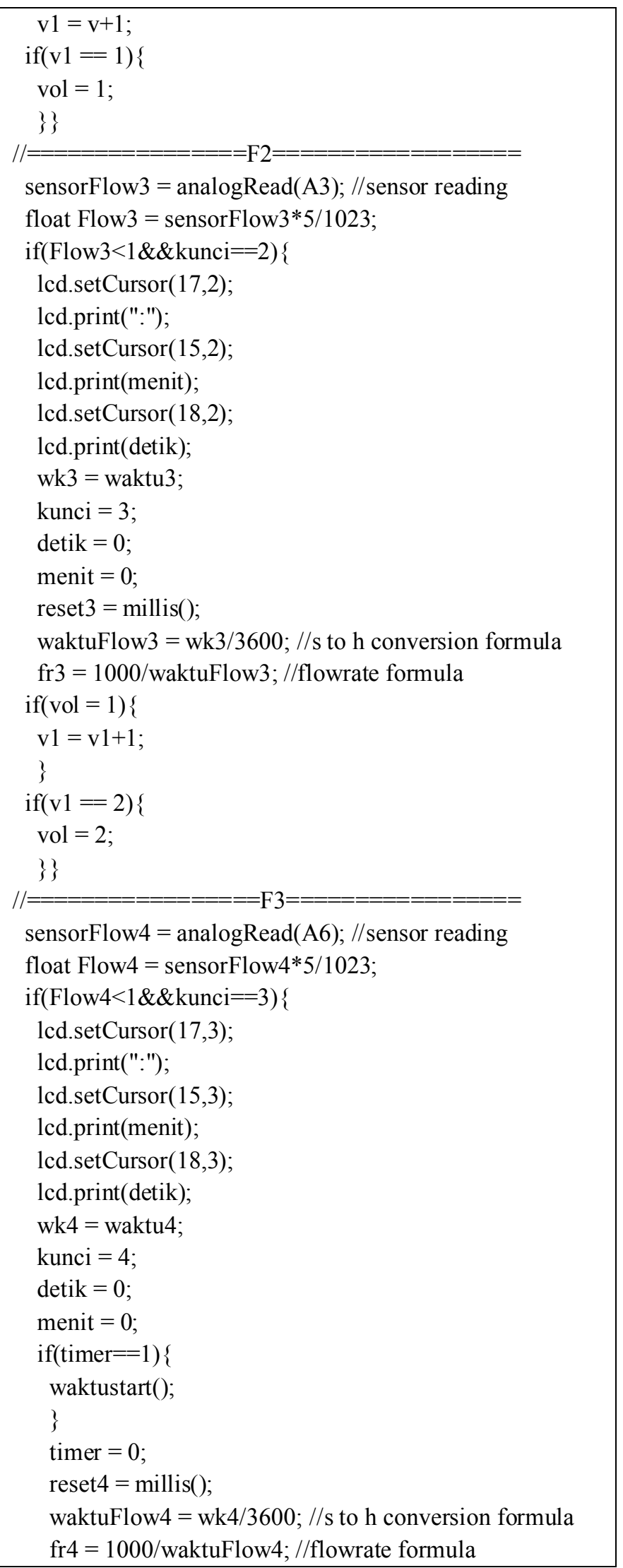

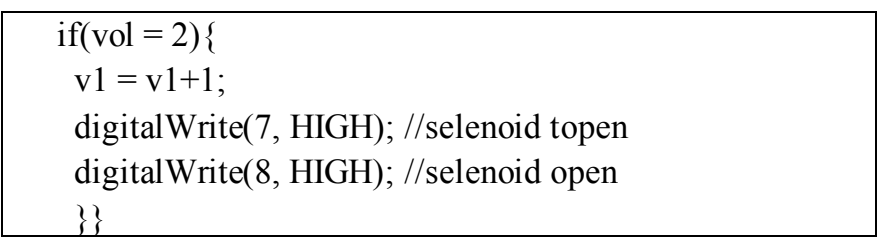

In this program, "sensorFlow2" is an infrared photodiode sensor that shows the results of the first calibration. "SensorFlow3" shows the results of the second calibration, and "sensorFlow4" shows the results of the third calibration. The output of these three sensors will go to the comparator input and, from the comparator output will go to pins A2, A3, and A6 on Arduino. The results of the acquisition of time on each sensor then enter into the flow velocity formula.

\section{Measurement Result of Infrared Photodiode Sensor at Comparator Output}

The measurement of the infrared photodiode sensor is done by measuring the comparator output (Table I). In this circuit, there are 4 outputs obtained from the comparison of the input voltage from the sensor and the reference voltage.

TABLE I. MEASUREMENT Result Of INFRAREd PHotodiode SENSOR AT THE COMPARATOR OUTPUT

\begin{tabular}{ccc}
\hline Sensor & Not Blocked by Water & Blocked by Water \\
\hline 1 & 2.63 Volt & 0.02 Volt \\
2 & 3.27 Volt & 0.00 Volt \\
3 & 3.20 Volt & 0.00 Volt \\
4 & 3.11 Volt & 0.01 Volt \\
\hline
\end{tabular}

D. Measurement Result of Multiturn Resistance

Multiturn resistance measurements are carried out by measuring the input pin and multiturn output pin (Table II).

TABLE II. MEASUREMENT Result Of Multiturn Resistance

\begin{tabular}{cc}
\hline Multiturn & Resistance $(\mathrm{K} \Omega)$ \\
\hline 1 & 88.5 \\
2 & 5.7 \\
3 & 13 \\
4 & 13.8 \\
\hline
\end{tabular}

E. Measurement Result of Syringe Pump Using Infusion Device Analyzer

Syringe pump performance measurement is done to determine the performance of the Infusion Device Analyzer. Syringe Pump performance data retrieval is done in 3 settings, namely $10 \mathrm{ml} /$ hour as much as 1 -time measurement, $50 \mathrm{ml} /$ hour as much as two times the measurement, and $100 \mathrm{ml} /$ hour as 
much as two times the measurement. Each measurement produces three calibration results (Table III).

TABle III. Measurement Reasult Of Syringe Pump Performance

\begin{tabular}{l|c|c|c}
\hline \multirow{2}{*}{ Set Flow } & \multicolumn{3}{|c}{ Measurement Result $(\mathrm{ml} / \mathrm{h})$} \\
\cline { 2 - 4 } & I & II & III \\
\hline \multirow{2}{*}{$10 \mathrm{ml} / \mathrm{h}$} & 9.90 & 8.93 & 9.26 \\
\hline \multirow{2}{*}{$50 \mathrm{ml} / \mathrm{h}$} & 50.00 & 43.48 & 47.62 \\
\cline { 2 - 4 } & 47.62 & 43.48 & 47.62 \\
\hline \multirow{2}{*}{$100 \mathrm{ml} / \mathrm{h}$} & 111.11 & 90.91 & 100.00 \\
\cline { 2 - 4 } & 83.33 & 90.91 & 100.00 \\
\hline
\end{tabular}

TABLE IV

THE AVERAGE AND ERROR MEASUREMENT OF THE SYRINGE PUMP ON FLOWRATE PARAMETERS

\begin{tabular}{cccc}
\hline No & Flowrate $(\mathrm{ml} / \mathrm{h})$ & Mean $(\mathrm{ml} / \mathrm{h})$ & Error $(\%)$ \\
\hline 1 & 10 & 9.36 & 6.4 \\
2 & 50 & 46.64 & 6.72 \\
3 & 100 & 96.04 & 3.96 \\
\hline
\end{tabular}

\section{DISCUSSION}

In this study, researchers measured the flow rate at the TOP5300 syringe pump. TABLE III shows that the measurements were carried out at a flow rate setting of $10 \mathrm{ml} /$ hour with onetime data collection at a setting of 50 and $100 \mathrm{ml} /$ hour with two times each data collection. TABLE IV shows the measurement results at the setting of $10 \mathrm{ml} /$ hour yields an average of 9.36 $\mathrm{ml} /$ hour with an error value of $6.4 \%$. At a setting of $50 \mathrm{ml} /$ hour produces an average of $46.64 \mathrm{ml} /$ hour with an error value of $6.72 \%$, and at a setting of $100 \mathrm{ml} /$ hour produces an average of $96.04 \mathrm{ml} /$ hour with an error value of $3.96 \%$. When referring to the measurement results on TABLE IV, this tool is said to be unfit for use because it has a high error value. However, the truth cannot be ascertained because the researcher did not compare the measurement results with standard measuring instruments. When compared with previous studies [4], with the use of the same sensor and system, this study experienced a decrease in the value of the resulting error. The decrease is the level of accuracy, and the precision of this device can be said to below, and it can be seen in TABLE IV. This can occur due to improper placement of sensors. The presence of air bubbles during the measurement process also affects the results of sensor readings. In addition, it is possible that the flow velocity generated by the motor on the syringe pump is unstable. In a practical system, this research can actually speed up the measurement time because this device can produce three calibration results in one measurement at the same flow rate setting. Although it can produce three calibration results, when referring to the measurement results on TABLE IV, this tool is said to be unfit for use because it has a high error value. However, the truth cannot be ascertained because the researcher did not compare the measurement results with standard measuring instruments.

\section{CONCLUSION}

The purpose of the current study was to show the development of a flow rate calibrator that displays three calibration results in one measurement at the same setting. This research has found that a photodiode and infrared can be flow rate detectors. The study uses programming with Arduino Nano to create the desired system and is displayed on an LCD character 2004A. This study has an average error value of 5.69\%, which means it exceeds the ECRI 416-0595 tolerance limit of $\pm 5 \%$. In summary, the study unveils the device does not meet the standards and cannot be implemented as an infusion pump calibrator and syringe pump device. A further experimental investigation is needed to reduce the value of errors, improve systems and mechanics, display the results on LCD graphics, and increase storage.

\section{REFERENCE}

[1] F. G. Chen, J. Y. Wang, S. Chen, S. C. Tu, and K. Y. Chen, "A hang-andplay intravenous infusion monitoring system," Proc. - 3rd Int. Conf. Appl. Comput. Inf. Technol. 2nd Int. Conf. Comput. Sci. Intell. ACIT-CSI 2015, pp. 278-281, 2015.

[2] J. Ma et al., "A new algorithm of drop speed measuring of infusion monitoring device," Proc. - 2013 Int. Conf. Comput. Sci. Appl. CSA 2013, pp. 229-232, 2013.

[3] N. Thongpance and K. Roongprasert, "Design and construction of infusion device analyzer," BMEiCON 2014 - 7th Biomed. Eng. Int. Conf., 2015.

[4] S. Pintasari, "Rancang Bangun Infusion Pump Analyzer," vol. 1, no. 1, pp. 1-6, 2019.

[5] M. I. Ali, "Designing a Low-Cost and Portable Infusion Pump," 2019 4th Int. Conf. Emerg. Trends Eng. Sci. Technol. ICEEST 2019, 2019.

[6] R. Assuncao et al., "Developing the control system of a syringe infusion pump," Proc. 2014 11 th Int. Conf. Remote Eng. Virtual Instrumentation, REV 2014, no. February, pp. 254-255, 2014.

[7] S. S. Alagundagi, K. Pasala, and M. Arora, "Monitoring," pp. 688-692.

[8] V. Suri, R. Gupta, G. Sharma, and K. Suri, "An unusual cause of ischemic stroke - Cerebral air embolism," Ann. Indian Acad. Neurol., vol. 17, no. 1, pp. 89-91, 2014.

[9] Y. Zhang, Y. Yao, Z. Wu, W. Zhang, Y. Chen, and H. Li, "Research on intelligent infusion device control system based on chip microcomputer," Proc. - 2010 Int. Forum Inf. Technol. Appl. IFITA 2010, vol. 1, pp. 301304, 2010.

[10] M. A. Khan, S. Tehami, and O. Mazhar, "Designing of microcontroller based Syringe Pump with variable and low delivery rates for the administration of small volumes," 2015 IEEE 21st Int. Symp. Des. Technol. Electron. Packag. SIITME 2015, pp. 135-138, 2015.

[11] Menteri Kesehatan Republik Indonesia, "Permenkes Nomor 54 tahun 2015 Tentang Pengujian dan Kalibrasi Alat Kesehatan,” vol. 13, no. 3. pp. $1-32,2015$.

[12] N. Thongpance, Y. Pititeeraphab, and M. Ophasphanichayakul, "The design and construction of infusion pump calibrator," 5th 2012 Biomed. Eng. Int. Conf. BMEiCON 2012, vol. 100, pp. 3-5, 2012.

[13] ECRI, "Health Device Inspection and Preventive Maintenance System, Infusion Device," pp. 196-201.

[14] E. U. Reach, "5mm photodiode PD333-3B/H0/L2," pp. 1-7, 2016.

[15] Everlight, "Technical Data Sheet 5mm Infrared LED , T-1 3/4," Everlight Electron. Co. LTD, pp. 1-7, 2005. 
